\title{
Recent advances in recreation ecology and the implications of different relationships between recreation use and ecological impacts
}

\author{
Christopher A Monz ${ }^{1 *}$, Catherine M Pickering ${ }^{2}$, and Wade L Hadwen ${ }^{3}$
}

Recreation ecology - the study of the environmental consequences of outdoor recreation/nature-based tourism activities and their effective management - is an emerging field of global importance. A primary research generalization in this field, the use-impact relationship, is commonly described as curvilinear, with proportionally more impact from initial recreation/tourism use. This finding has formed the basis of visitor management strategies in parks, wilderness, and protected areas in many parts of the world. In this paper, however, we argue that the current generalization may be an oversimplification derived from one ecological response: the response of vegetation cover in some plant communities to trampling. Use-response functions for other plant communities, wildlife, soils, and aquatic/marine systems, for example, can differ and require alternative management strategies for sustainable use. On the basis of the available literature, we propose several alternative response relationships.

Front Ecol Environ 2013; 11(8): 441-446, doi:10.1890/120358 (published online 29 Aug 2013)

W orldwide, recreation and tourism activities in parks, wilderness, and protected areas continue to show trends of increasing participation (Cordell 2008; Balmford et al. 2009). Associated with this rise in visitation are anthropogenic disturbances that result in environmental impacts, which in turn raise concerns as to whether recreation and tourism activities in protected areas can be managed sustainably.

In response to these concerns, a specialized field of study - recreation ecology - has emerged. Recreation ecology began in earnest in the early 1960s (Wagar 1964) and is commonly defined as the study of the impacts of outdoor recreation and nature-based tourism activities in

\section{In a nutshell:}

- Experimental studies of outdoor recreation/nature-based tourism activities and their resultant ecological impacts have been generalized as a curvilinear use-impact relationship

- This generalization has guided visitor management strategies in many parks to minimize impacts

- The curvilinear relationship, while useful in characterizing some vegetation responses, does not adequately describe all vegetation responses or other important ecosystem effects

- Linear, exponential, and step function models may more adequately describe many ecosystem responses and consequently lead to alternative management strategies

${ }^{1}$ Department of Environment and Society, The Ecology Center, Utah State University, Logan, UT* (chris.monz@usu.edu); ${ }^{2}$ Environmental Futures Centre and Griffith School of Environment, Griffith University, Gold Coast, Australia; ${ }^{3}$ Australian Rivers Institute and Griffith School of Environment, Griffith University, Brisbane, Australia natural or semi-natural environments (Liddle 1997; Hammitt and Cole 1998). Several recent reviews have identified more than 1000 articles on recreation ecology published in the past few decades (Leung and Marion 2000; Buckley 2004; Monz et al. 2010; Steven et al. 2011; Newsome et al. 2012). Although recreation ecology research has been conducted throughout the world, most studies have occurred in North America, Europe, and Australia (Buckley 2005; Steven et al. 2011).

Research in recreation ecology has examined the impacts of hiking, camping, and other activities where use is concentrated, such as along formal trails or at highuse destinations, or dispersed, where visitors are not confined to specific routes or destinations (Figure 1). Research on concentrated-use includes examining changes along established trails and sites, including relating impacts to patterns of use-associated, environmental, and managerial factors (Leung and Marion 2000). By way of comparison, research on dispersed-use tends to examine recreation as a type of ecological disturbance and often relies on controlled experimental designs to quantify the resistance (ability to withstand disturbance) and resilience (ability to rebound after disturbance) of ecosystems to particular types of use (Monz et al. 2010).

The impact of trampling on vegetation is one of the most common and systematically researched topics in recreation ecology (eg Wagar 1964; Bayfield 1971; Cole and Bayfield 1993; Hill and Pickering 2009; Pickering et al. 2010). This includes assessing the response of vegetation and soils to increasing levels and different types of use. Experimental trampling protocols (eg Cole and Bayfield 1993) have been widely used to examine a range of factors that influence the intensity and extent of impacts including: (1) amount of use, (2) type and behav- 


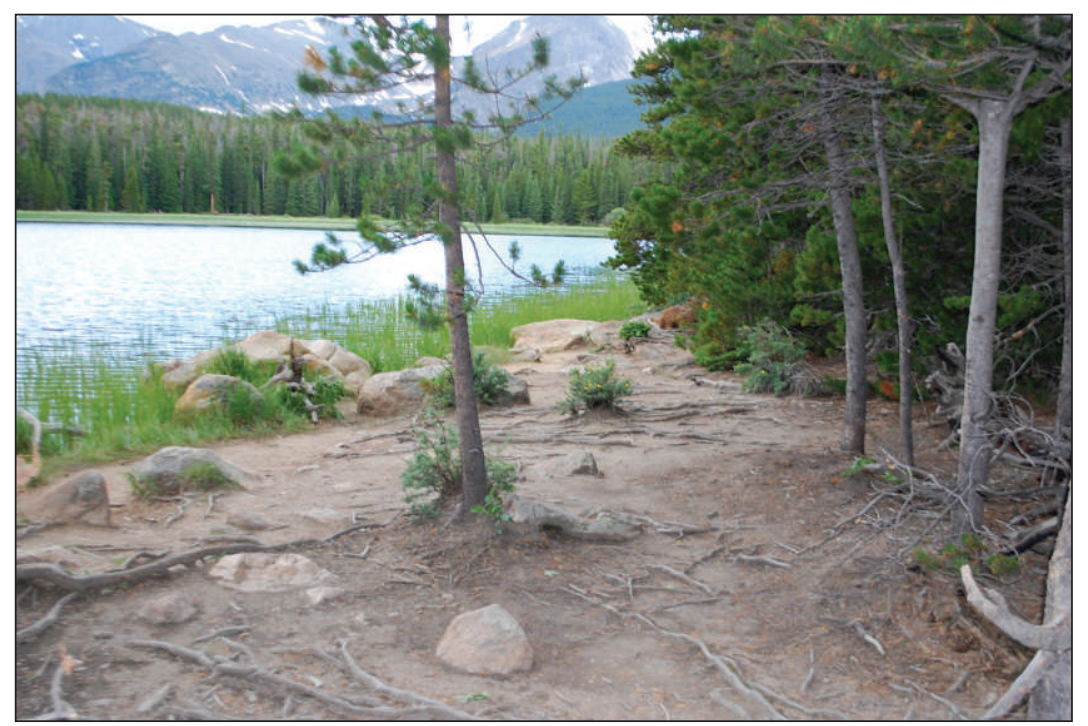

Figure 1. Common vegetation, soil, and tree disturbance from nature-based recreation/tourism activities in parks and protected areas. Disturbance to aquatic systems is also common, due in part to their desirability as destinations for visitors. more dynamic and spatially diffuse than these generalizations imply (Kim and Daigle 2012). Regardless, the ideas in this paper provide an important update on current thinking in recreation ecology and indicate directions for future research to inform the development of management strategies.

\section{Relationship between use and impact for vegetation}

As mentioned, the relationship between amount of recreation use and impact on vegetation and soil is often expressed as asymptotic and curvilinear (Figure 2a). This relationship was first described by Frissell and Duncan (1965), further investigated by Cole (1981), and supported by a number of subsequent studies (eg Monz 2002; Hill and Pickering 2009), most of which examined ior of use, (3) timing of use, and (4) type and condition of the environment. Because protected area managers can influence some of these factors, this research has contributed substantially to the development of sustainable visitor management strategies (Hammitt and Cole 1998).

In this paper, we focus on the most commonly studied factor relating to the ecological impacts of recreation activities - the amount of use. The relationship between increasing use and ecological change is often generalized as a curvilinear, asymptotic relationship (Figure 2a; Hammitt and Cole 1998). This generalized form of the relationship has been used to formulate management strategies in a range of parks, wilderness, and protected areas (Hammitt and Cole 1998; Newsome et al. 2012). Studies examining the efficacy of management based on the curvilinear response have demonstrated both success and failure in limiting ecological impacts (eg Cole et al. 2008); moreover, these studies have typically relied on a limited set of ecological variables (such as vegetation cover) upon which to base findings. We suggest that the curvilinear response may not describe the use-impact relationship for many important ecological responses, including the response of all types of vegetation to trampling. Consequently, some management strategies may need to be modified because they could be unduly limiting recreation use or, alternatively, causing undesirable impacts.

On the basis of recent research, here we propose a conceptual framework of likely response relationships to guide future research and management. We provide examples of these relationships largely from experimental research where ecological responses, particularly initial resistance to disturbance, have been examined in relation to quantified levels of recreational use. We acknowledge that there may be relationships other than the ones identified here. In addition, recent long-term studies suggest that, in certain circumstances, ecological change may be either vegetation and soil responses to trampling under controlled conditions or changes in vegetation and soil on sites with known levels of use. These results and the model of the relationship between use and impact indicate that on previously undisturbed sites, even small increases in the amount of initial use result in dramatic increases in impacts (Cole 1981; Hill and Pickering 2009). Consequently, where use levels are low, small differences in the amount of use can lead to substantial differences in impact. Alternatively, where use levels are high, additional impact has proportionally less effect. This relationship underpins strategies that seek to confine use to designated trails and sites in areas popular for nature-based tourism and recreation. Commonly called "confinement" strategies, these approaches assume that once a site is extensively disturbed, impacts will not change considerably despite substantial increases in use. Although the literature suggests some management challenges with confinement strategies (Cole et al. 2008), typically they can assist in limiting the total area impacted by visitors (Hammitt and Cole 1998; Newsome et al. 2012).

In contrast to the curvilinear model, at least two studies (Cole and Monz 2004; Growcock 2005) observed a sigmoidal response to use (Figure $2 \mathrm{~b}$ ) as opposed to the more commonly reported single asymptote at the top of the curve. Sigmoidal models are useful in various ecological applications (eg Kuznar 2002), and the use of this model in recreation disturbance was suggested as a possibility in some earlier work on the subject (Liddle 1975; Cole 1992). This has practical implications for managing areas with dispersed low levels of use, particularly on non-vegetated substrates or trampling-resistant vegetation. In these cases, it may be more likely to effectively manage low levels and limit ecological change than the curvilinear response suggests. Growcock's (2005) work further suggests that along the stress-response curve, different 
impacts may be more pronounced at different levels of use (ie that plant physiological stress precedes mechanical damage and loss of plant cover). Also, this research indicates that more sensitive techniques for assessing change may be required than those previously used in trampling studies. Recent work addressing this issue has modeled the shape of the relationship with more replicates and levels of use and has revealed that, in more resistant plant communities, the disturbance-use relationship was closer to linear than curvilinear (Hill and Pickering 2009).

\section{Responses in other systems}

Recreation ecology researchers are increasingly examining the effects of recreation/tourism activities beyond those of trampling on vegetation and soils, including research on aquatic systems, wildlife, and to a lesser extent, air quality. Despite several recent syntheses of this research (Buckley 2004; Monz et al. 2010; Steven et al. 2011; Newsome et al. 2012), few generalizations have emerged. Here we draw on examples of this research, particularly from aquatic systems and wildlife that suggest different use-impact responses than the vegetation-soil models (described earlier) that tend to underpin visitor management strategies.

\section{Aquatic systems}

Since the mid-1990s, recreation ecology research has examined a diversity of recreation uses and their impacts on organisms, physical attributes, and chemical processes in marine systems. Two topics that have received particular attention are: (1) trampling impacts, including those from diving on intertidal and coral reef communities (eg Schlacher and Thompson 2012), and (2) boating impacts, including pollutants and physical damage to marine environments (eg Bishop and Chapman 2004; Milazzo et al. 2004a; Herbert et al. 2009). Although few studies have specifically focused on recreational boating, pertinent literature reviews conclude that boating can have considerable effects on marine environments, particularly where use levels are high. So far, few generalizations regarding the use-impact relationship have been developed. However, the complexity of responses was highlighted by Schlacher and Thompson (2012), who reported no impacts, linear impacts, and curvilinear impacts on macroinvertebrate communities subjected to trampling on unvegetated sandy beaches.
Likewise, impacts of a range of recreational activities on freshwater environments have also been examined (Hammitt and Cole 1998; Hadwen et al. 2010), including the effects of swimming (Hadwen et al. 2003, 2005; Hadwen and Bunn 2004) and recreational power boating and water skiing (Mosisch and Arthington 2004). In addition to direct physical disturbance from recreational uses of the water bodies, inland freshwater environments are subject to nutrient influx, pathogen introduction, and sedimentation (Hadwen et al. 2005, 2010). While numerous site- and activity-specific influences exist, recreation effects on freshwater quality appear to be more density dependent (eg Figure 3a) than in terrestrial environments (Hadwen et al. 2005). For example, Hadwen and Bunn (2004) found that increasing numbers of visitations to dune lakes on Australia's Fraser Island was positively correlated with a shift in the aquatic food web toward a stronger reliance on algal resources, the production of which is stimulated by nutrient inputs from visitors (Hadwen and Bunn 2005; Hadwen et al. 2005).

\section{Highly resistant environments}

Highly resistant substrates can obviously display a different relationship between use and impact than that observed for vegetated areas. These types of substrates 


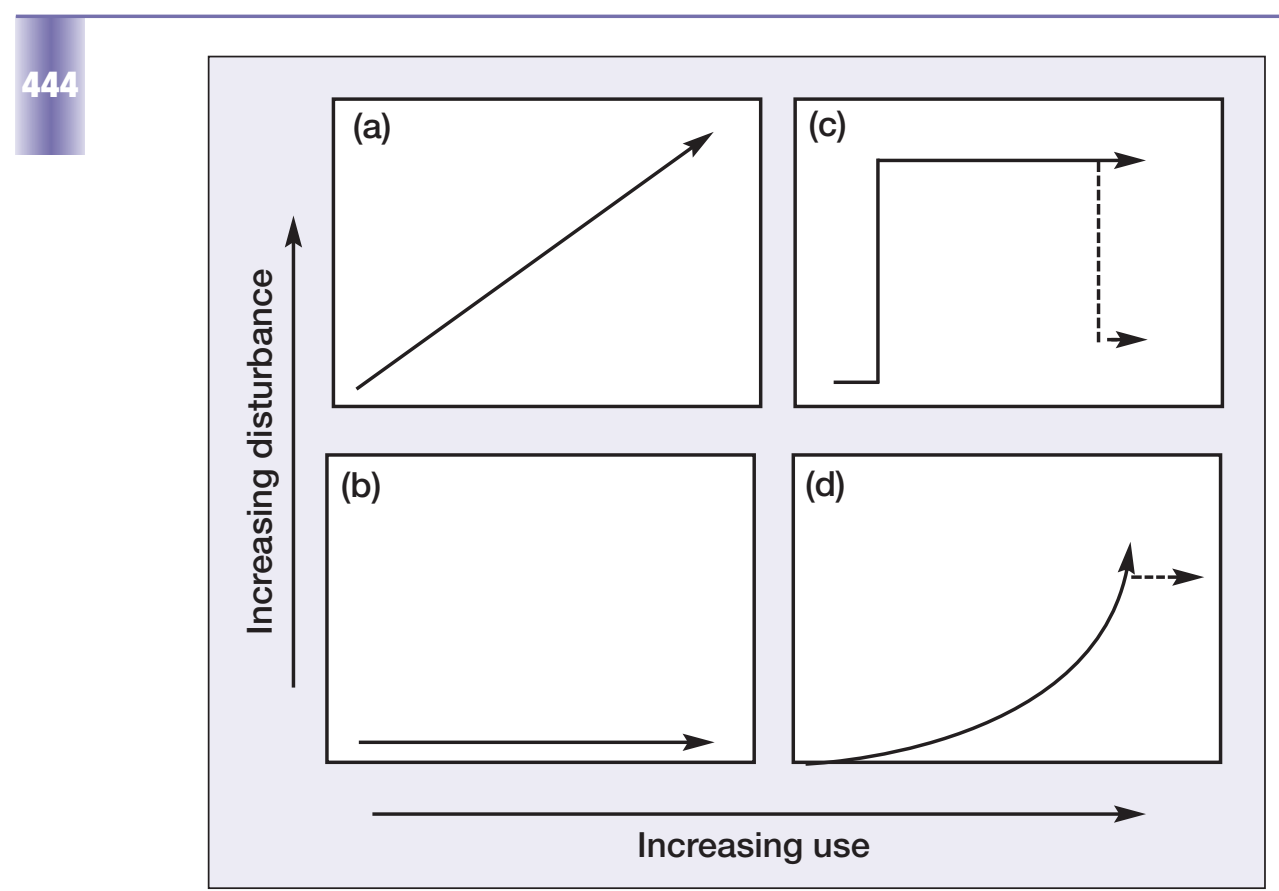

Figure 3. Hypothetical response curves for various ecological responses to recreation disturbances: (a) Escherichia coli concentrations in aquatic ecosystems (Hadwen et al. 2010); (b) use on a highly resistant substrate (ie exposed rock; Hill and Pickering 2006); (c) wildlife "fight or flight" response (Knight and Gutzwiller 1995; Buckley 2004); (d) recreational use and soil erosion (Liddle 1997). Dashed lines represent alternate responses: in (c), a return of individuals upon cessation of disturbance; in $(d)$, complete soil loss. and other activities (Weaver and Dale 1978; Deluca et al. 1998). Relational analysis has also examined soil loss on maintained trail systems and examined factors that may influence soil loss (Olive and Marion 2009).

From this literature, several use-soil-loss relationships emerge, including linear and exponential relationships (Figure 3, a and d). Where surfaces are hard, as discussed above, the relationship is flat, but where soils are soft and very deep, as in alpine humus soils in valley floors, the relationship can be linear and steep. Furthermore, as Liddle (1997) described, recreational disturbance is often the "trigger" for soil erosion by damaging the protective vegetation and litter cover, resulting in direct mechanical disturbance to exposed soil horizons and subsequent erosion from wind and water, leading to rapid soil loss.

\section{Wildlife}

Despite several reviews (Knight and Gutzwiller 1995; Hammitt and Cole 1998; Steidl and Powell 2006; Steven et al. 2011), it is difficult to make generalizations about can occur naturally (eg exposed rock on a mountain summit or on rocky shores), can result from excessive use eliminating vegetation and compacting soils, or can be created by park agencies via the maintenance of trails and sites with resistant substrates (eg gravel, rock). Concentrating use on these hardened surfaces reduces ecological change, and sites characterized by these hard surfaces will exhibit a flat (zero slope) relationship with increasing use (Figure 3b). An example of how concentrated use of these surfaces can protect vulnerable ecosystems is seen in the application of raised walkways, where complete native vegetation cover can exist under the walkway despite high levels of visitor use (Hill and Pickering 2006). As a result, changes in use will have no effect on the vegetation or soils under the walkway. A different relationship between use and impact on a hardened surface was seen in a study examining the effects of human trampling on the tolerance of algal communities on rocky shorelines (Milazzo et al. 2004b). In this instance, impacts were more subtle than those in some terrestrial systems, and some relationships may more closely resemble the curvilinear relationship (Figure 2a) than what has been typically assumed (Figure 2b).

\section{Soil loss}

The impact of increasing use on soil is highly variable. Experimental studies have focused on the use-soil-loss relationship in association with trampling (Kuss 1983) the effects of recreation on wildlife, due in part to the diversity of recreational activities, study methodologies, and observed responses. Much of the research has focused on behavioral responses of wildlife to visitors (Anthony et al. 1995; Clua et al. 2010; Steven et al. 2011) and subsequent alterations in species composition and diversity (Knight and Gutzwiller 1995; Steven et al. 2011). However, a growing number of species-specific studies have examined the effect of recreation and tourism activities on energetic and physiological stresses (Bélanger and Bedard 1990; Semeniuk et al. 2009; Marechal et al. 2011; Steven et al. 2011) and changes in reproduction rates and population levels (Burger 1995; Orams 2002; Steven et al. 2011). Recreation and tourism can also result in wildlife becoming dependent on humans as a source of food; such a dependence can be detrimental both for wildlife and visitors (Orams 2002; Newsome et al. 2012).

One widely reported generalization regarding increased use and impact is birds taking flight when approached by tourists (Buckley 2004; Steven et al. 2011). Sometimes described as a "flight or fight" response (Knight and Gutzwiller 1995), this kind of behavior results in a step relationship between use and impact, with a sudden reaction from the pre-disturbance steady state (Figure 3c) as numbers increase or visitors approach the animals (Buckley 2004; Steven et al. 2011). It can also induce complete avoidance of areas that are more intensively used by people, resulting in decreased animal diversity close to high-use sites (Buckley 2004; Steven et al. 2011; Newsome et al. 2012). 


\section{Conclusions}

This paper advances recreation ecology theory by proposing new generalizations about the relationship between use and impacts, enhancing both future research opportunities and improving management. The original use-impact relationship stands as one of the few well-developed research generalizations in this field. This is largely due to research that focused on easily observable ecological responses, such as changes in vegetation cover and rapid assessment techniques, rather than more sensitive measurements (Monz et al. 2010). More recent research suggests several alternative models for some ecological responses. Future research could more directly model the use-response relationship through more sensitive methods of measurement and improved experimental designs.

The alternative models proposed also highlight the need for caution while employing standard dispersal and confinement management strategies. Although successful in minimizing the proliferation of certain impacts such as vegetation loss in many environments, these approaches may have unintended consequences, especially in situations where impacts do not "level off" with increased use.

Finally, we emphasize that increasing intensity of use is just one important factor influencing recreation/tourism impacts. Management decisions should not be solely based on any one factor (eg limiting use numbers). For example, visitor behavior, degree of site hardening/maintenance, trail design, and environmental durability all affect the severity and extent of impacts and may be more important than use level in some circumstances (Hammitt and Cole 1998; Olive and Marion 2009). Moreover, protected area management involves integrating ecological, social/cultural, and managerial components to achieve the best possible overall outcome. Here, we have established that managers cannot simply accept that all ecological impacts follow a curvilinear response and then assume that a confinement strategy will minimize unacceptable changes.

\section{Acknowledgements}

We thank our fellow recreation ecologists, including J Marion, Y-F Leung, R Buckley, D Newsome, and G Dixon, for helpful discussions of the concepts in this paper. We especially acknowledge D Cole and financial support from the US Department of Agriculture Forest Service that enabled this international collaboration. CAM also thanks the Utah State Agricultural Experiment Station for supporting this research.

\section{References}

Anthony RG, Steidl RJ, and McGarigal K. 1995. Recreation and bald eagles in the Pacific Northwest. In: Knight RL and Gutzwiller KJ (Eds). Wildlife and recreationists: coexistence through management and research. Washington, DC: Island Press.

Balmford A, Beresford J, Green J, et al. 2009. A global perspective on trends in nature-based tourism. PLoS Biol 7: e1000144.

Bayfield NG. 1971. Some effects of walking and skiing on vegetation at Cairngorm. In: Duffey E and Watt AS (Eds). The scientific management of plant and animal communities for conservation. Oxford, UK: Blackwell.

Bélanger L and Bedard J. 1990. Energetic cost of man-induced disturbance to staging snow geese. J Wildlife Manage 54: 36-41.

Bishop MJ and Chapman MG. 2004. Managerial decisions as experiments: an opportunity to determine the ecological impact of boat-generated waves on macrobenthic infauna. Estuar Coast Shelf S 61: 613-22.

Buckley R. 2004. Environmental impacts of off-highway vehicles. In: Buckley R (Ed). Environmental impacts of ecotourism. Oxon, UK: CABI Publishing.

Buckley RC. 2005. Recreation ecology research effort: an international comparison. Tourism Recreation Research 30: 99-101.

Burger J. 1995. Beach recreation and nesting birds. In: Knight RL and Gutzwiller KH (Eds). Wildlife and recreationists: coexistence through management and research. Washington, DC: Island Press.

Clua E, Buray N, Legendre P, et al. 2010. Behavioural response of sicklefin lemon sharks Negaprion acutidens to underwater feeding for ecotourism purposes. Mar Ecol-Prog Ser 414: 257-66.

Cole DN. 1981. Managing ecological impacts at wilderness campsites and evaluation of techniques. J Forest 79: 86-89.

Cole DN. 1992. Modeling wilderness campsites: factors that influence amount of impact. Environ Manage 16: 255-64.

Cole DN and Bayfield NG. 1993. Recreational trampling of vegetation: standard experimental procedures. Biol Conserv 63: 209-15.

Cole DN and Monz CA. 2004. Spatial patterns of recreation impact on experimental campsites. J Environ Manage 70: $73-84$.

Cole DN, Foti P, and Brown M. 2008. Twenty years of change on campsites in the backcountry of Grand Canyon National Park. Environ Manage 41: 959-70.

Cordell HK. 2008. The latest on trends in nature-based outdoor recreation and tourism. Forest History Today Spring: 4-10.

Deluca TH, Patterson WA, Freimund WA, and Cole DN. 1998. Influence of llamas, horses, and hikers on soil erosion from established recreation trails in western Montana, USA. Environ Manage 22: 255-62.

Frissell SS and Duncan DP. 1965. Campsite preference and deterioration in the Quetico-Superior canoe country. J Forest 65: 256-60.

Growcock AJW. 2005. Impacts of camping and trampling on Australian alpine and subalpine vegetation ( $\mathrm{PhD}$ dissertation). Gold Coast, Australia: Griffith University.

Hadwen WL and Bunn SE. 2004. Tourists increase the contribution of autochthonous carbon to littoral zone food webs in oligotrophic dune lakes. Mar Freshwater Res 55: 701-08.

Hadwen WL and Bunn SE. 2005. Food web responses to low-level nutrient and ${ }^{15} \mathrm{~N}$-tracer additions in the littoral zone of an oligotrophic dune lake. Limnol Oceanogr 50: 1096-05.

Hadwen WL, Arthington AH, and Boon PI. 2010. Guidelines for design and implementation of monitoring programs to assess visitor impacts in and around aquatic ecosystems within protected areas. Gold Coast, Australia: Sustainable Tourism Cooperative Research Centre Press.

Hadwen WL, Arthington AH, and Mosisch TD. 2003. The impact of tourism on dune lakes on Fraser Island, Australia. Lakes Reserv Res Manage 8: 15-26.

Hadwen WL, Bunn SE, Arthington AH, and Mosisch TD. 2005. Within-lake detection of the effects of tourist activities in the littoral zone of oligotrophic dune lakes. Aquat Ecosyst Health 8: 159-73.

Hammitt WE and Cole DN. 1998. Wildland recreation: ecology and management (2nd edn). New York, NY: John Wiley. 
Herbert RJH, Crowe TP, Bray S, and Sheader M. 2009. Disturbance of intertidal soft sediment assemblages caused by swinging boat moorings. Hydrobiologia 625: 105-16.

Hill W and Pickering CM. 2006. Vegetation associated with different walking track types in the Kosciuszko alpine area, Australia. J Environ Manage 78: 24-34.

Hill R and Pickering CM. 2009. Differences in resistance of three subtropical vegetation types to experimental trampling. J Environ Manage 90: 1305-12.

Kim MK and Daigle JJ. 2012. Monitoring of vegetation impact due to trampling on Cadillac Mountain summit using high spatial resolution remote sensing data sets. Environ Manage 50: 956-68.

Knight RL and Gutzwiller KJ. 1995. Wildlife and recreationists: coexistence through management and research. Washington, DC: Island Press.

Kuss FR. 1983. Hiking boot impacts on woodland trails. J Soil Water Conserv 38: 119-21.

Kuznar LA. 2002. Evolutionary applications of risk sensitivity models to socially stratified species: comparison of sigmoid, concave, and linear functions. Evol Hum Behav 23: 265-80.

Leung Y-F and Marion JL. 2000. Recreation impacts and management in wilderness: a state-of-knowledge review. In: Cole DN, McCool SF, Borrie WT, and O'Loughlan J (compilers). Wilderness science in a time of change conference - volume 5: wilderness ecosystems, threats and management. Missoula, MT: 23-27 May 1999. Ogden, UT: USDA Forest Service Rocky Mountain Research Station. Proceedings RMRS-P-15-Vol-5.

Liddle MJ. 1997. Recreation ecology: the ecological impact of outdoor recreation and ecotourism. London, UK: Chapman and Hall.

Liddle MJ. 1975. A selective review of the ecological effects of human trampling on natural ecosystems. Biol Conserv 8: 251-55.

Marechal LS, Semple B, Majolo M, et al. 2011. Impacts of tourism on anxiety and physiological stress levels in wild male barbary macaques. Biol Conserv 144: 2188-93.

Milazzo MF, Badalamenti F, Ceccherelli G, and Chemelo R. 2004a. Boat anchoring on Posidonia oceanica beds in a marine protected area (Italy, western Mediterranean): effect of anchor types in different anchoring stages. J Exp Mar Biol Ecol 299: $51-62$.

Milazzo MF, Badalamenti F, Riggio S, and Chemelo R. 2004b.
Patterns of algal recovery and small-scale effects of canopy removal as a result of human trampling on a Mediterranean rocky shallow community. Biol Conserv 117: 191-202.

Monz CA. 2002. The response of arctic tundra plant communities to human trampling disturbance. J Environ Manage 64: 207-17.

Monz CA, Cole DN, Marion J, and Leung Y-F. 2010. Sustaining visitor use in protected areas: future opportunities in recreation ecology research based on the USA experience. Environ Manage 45: 551-62.

Mosisch TD and Arthington AH. 2004. Impacts of recreational power-boating on freshwater ecosystems. In: Buckley R (Ed). Environmental impacts of ecotourism. Oxon, UK: CABI Publishing.

Newsome D, Moore SA, and Dowling RK. 2012. Natural area tourism: ecology, impacts, and management (2nd edn). Clevedon, UK: Channel View Books.

Olive ND and Marion JL. 2009. The influence of use-related, environmental and managerial factors on soil loss from recreational trails. J Environ Manage 90: 1483-93.

Orams MB. 2002. Feeding wildlife as a tourism attraction: a review of issues and impacts. Tourism Manage 23: 281-93.

Pickering CM, Hill R, Newsome D, and Leung Y-F. 2010. Comparing hiking, mountain biking and horse riding impacts on vegetation and soils in Australia and the United States of America. J Environ Manage 91: 551-62.

Schlacher TA and Thompson L. 2012. Beach recreation impacts benthic invertebrates on ocean-exposed sandy shores. Biol Conserv 147: 123-32.

Semeniuk CAD, Bourgeon S, Smith SL, and Rothley KD. 2009. Hematological differences between stingrays at tourist and non-visited sites suggest physiological costs of wildlife tourism. Biol Conserv 142: 1818-29.

Steidl RJ and Powell BF. 2006. Assessing the effects of human activities on wildlife. George Wright Forum 23: 50-58.

Steven R, Pickering CM, and Castley G. 2011. A review of the impacts of nature based recreation on birds. J Environ Manage 92: 2287-94.

Wagar JA. 1964. The carrying capacity of wild lands for recreation. Washington, DC: Society of American Foresters. Forest Science Monograph 7.

Weaver T and Dale D. 1978. Trampling effects of hikers, motorcycles and horses in meadows and forests. J Appl Ecol 15: 451-57.

\section{TAKE THIS JOURNAL TO YOUR LIBRARIAN, PLEASE}

\section{Are you enjoying this issue of Frontiers?}

\section{If your library had a subscription, colleagues and students could enjoy it too.}

Please consider recommending Frontiers in Ecology and the Environment to your library.

Clip or copy the form below. Thank you for your support.

of

Library Recommendation Form

To Acquisition Librarian, Serials

From

Dept

Signature Date

I recommend the library subscribe to: Frontiers in Ecology and the Environment (ISSN 1540-9295)

To request a free sample issue of Frontiers in Ecology and the Environment, email Eric Gordon at eric@esa.org.

Order Frontiers by contacting ESA Headquarters at (202) 833-8773, online at www.esa.org, or through your subscription agent. 